\title{
PENGARUH PENAMBAHAN FLOKULAN DAN KOAGULAN MENGGUNAKAN METODE JAR TEST TERHADAP KUALITAS AIR BAKU
}

\author{
Akda Zahrotul Wathoni ${ }^{1}$, Ika Fitri Ulfindrayani ${ }^{2}$, Karya Hidayat ${ }^{3}$ \\ 1,3 Jurusan Teknik Industri, Fakultas Teknik dan Ilmu Komputer, Universitas Buana Perjuangan Karawang \\ Jl. HS. Ronggowaluyo Telukjambe Timur Karawang, \\ ${ }^{2}$ Jurusan Teknik Elektro, Fakultas Sains dan Teknologi, Universitas Teknologi Surabaya \\ Jl. Balongsari Praja V No.1 Surabaya \\ Email: akda.zw@ubpkarawang.ac.id
}

\begin{abstract}
Water is an essential need for all living things on earth. For industrial activities, water has an important role for production and non-production activities. The use of water at a paper company in Karawang is required around $7000 \mathrm{~m} 3$ per day. So that the company is required to have a water treatment plant to meet the needs of production and non-production water. The function of the raw water treatment plant (Raw water Treatment) in the company aims to get good water quality from its water source, namely Citarum river water. So it is necessary to analyze the condition of the water first by means of the Jar test. With the Jar test, the optimum dose can be determined in the addition of coagulant and flocculant solutions. In addition, the jar test with the addition of flocculants and coagulants can also reduce the $\mathrm{pH}$ and turibidity of raw water. From the results of statistical tests using a paired sample test, $\mathrm{pH}$ and Turbidity levels have a significant change with a value of (Sig.) < 0.05, so HO is rejected. The method of adding flocculants and coagulants with the Jar Test method can reduce $\mathrm{pH}$ levels of $10 \%$ and Turbidity of $95 \%$.
\end{abstract}

Keywords: Raw Water; Raw Water Treatment Plant; Jar Test.

\begin{abstract}
ABSTRAK
Air merupakan kebutuhan penting untuk semua makhluk hidup di bumi. Untuk kegiatan industri air memiliki peran penting untuk kegiatan produksi dan non produksi. Penggunaan air pada salah satu perusahaan kertas di Karawang diperlukan sekitar $7000 \mathrm{~m}^{3}$ per harinya. Sehingga perusahaan tersebut dituntut memiliki instalasi pengolahan air untuk memenuhi kebutuhan air produksi dan non produksi. Fungsi instalasi pengolahan air baku (Raw water Treatment) di perusahaan tersebut bertujuan untuk mendapatkan kualitas air yang baik dari sumber airnya yaitu air sungai citarum. Maka diperlukan analisis kondisi air terlebih dahulu dengan cara Jar test. Dengan Jar test maka dapat ditentukan dosis optimum dalam penambahan larutan koagulan dan flokulan. Selain itu jar test dengan penambahan flokulan dan koagulan juga dapat menurunkan kadar pH dan turibidity air baku. Dari hasil uji statistika menggunakan paired sampel test kadar pH dan Turbidity memiliki perubahan yang sigifikat dengan nilai (Sig.) < 0,05 maka HO ditolak. Metode penambahan flokulan dan koagulan dengan metode Jar Test ini dapat menurukan kadar pH 10\% dan Turbidity 95\%.
\end{abstract}

Kata kunci: Air Baku; Instalasi Pengolahan Air Baku; Jar Test.

\section{PENDAHULUAN}

Pada era modern ini dengan bertambahnya jumlah populasi manusia dan kebutuhankebutuhan lainnya. Maka dengan berbagai macam teknologi untuk memenuhi kebutuhan tersebut Salah satu kebutuhan manusia yang paling penting adalah air. Air merupakan kebutuhan penting untuk semua makhluk hidup di bumi. Air memiliki peran penting dalam kegiatan industri baik itu untuk produksi dan non produksi. Untuk itu diperlukan penyediaan air bersih yang memenuhi standar 
perusahaan secara kuantitas harus memenuhi kebutuhan industri sehingga proses produksi tersebut dapat berjalan dengan baik (Sutrisno, 2010).

Perusahaan yang akan diamati adalah perusahaan memproduksi cigaratte paper dimana pada proses produksinya memerlukan air sekitar $7000 \mathrm{~m}^{3}$ per harinya. Oleh karna itu perusahaan tersebut membangun instalasi pengolahan air untuk memenuhi kebutuhan air. Instalasi Pengolahan Air (Water Treatment Plant) adalah suatu fasilitas untuk mengolah air baku menjadi air yang terstandar dari perusahaan untuk produksi dan non produksi. Rangkaian instalasi tersebut dirancang untuk mempermudah proses penjernihan air dalam mengaplikasikan teknik pengolahan air sehingga hasil pengolahan air dapat dimaksimalkan dan kualitas air pun dapat terjaga secara menyeluruh untuk kebutuhan produksi dan non produksi.

Water treatment plant di perusahaan tersebut terdiri dari Raw Water Treatment dan Waste Water Treatment. Pengamatan yang dilakukan adalah Raw water treatment. Raw water treatment ialah proses untuk penjernihan air sungai citarum dan air effluent untuk mengurangi tingkat turbidity yang tinggi. Sehingga diperlukan suatu proses penambahan kimia yaitu larutan koagulan dan foakulan. Kedua larutan ini berfungsi untuk menangkap flok-flok hingga menggumpal. Lalu akan ada proses sedimentasi di bak penyimpanan sebelum masuk ke filterisasi. Filterisasi yang digunakan yaitu sand filter dan carbon filter. Keduanya untuk menghilangkan kotoran, warna, dan bakteri.

Standar kualitas air yang sebaiknya masuk ke instalasi pengolahan air baku (Raw Water Tretment) adalah dengan kadar $\mathrm{pH}(6.5 \sim 7.5)$, Turbidity $(<1.5 \mathrm{NTU})$, Conductifity $(<350)$, dan free chlorine (0.1 0.3). Sumber air baku yang digunakan berasal dari air sungai citarum dan air hasil olahan di instalasi pengolahan air limbah yang disebut air effluent. Oleh karena itu harus menganalisis kondisi air terlebih dahulu dengan cara metode Jar test. Jar test adalah pengambilan sempel untuk percobaan yang berfungsi untuk menentukan dosis optimum untuk proses koagulasi dan flokulasi yang digunakan dalam proses pengolahan air baku.

\section{METODE PENELITIAN}

\section{Lokasi Penelitian}

Penelitian ini akan dilakukan penentuan dosis optimum larutan koagulan dan flokulan dengan menggunakan metode Jar Test pada instalasi pengolahan air baku di Perusahaan kertas yang berlokasi di Kabupaten Karawang Jawa Barat. Hal yang terkait dengan penelitian ini adalah mengenai kualitas air baku yang diterima oleh instalasi pengolahan air baku.

\section{Sumber Data}

Data yang digunakan dalam penelitian ini adalah data primer dan sekunder yang diperoleh dari water treatment plant di salah satu perusahaan kertas di Kabupaten Karawang. Data yang diperoleh terdiri dari data $\mathrm{pH}$ dan Turbidity sebelum dan setelah pengujian jar test.

\section{Metode Pengujian Jar Test}

Bahan yang digunakan pada penelitian ini meliputi sampel air baku, bahan flokulan dan koagulan (alum dan EA608), aquadest. Sedangkan peralatan yang digunakan meliputi $\mathrm{pH}$ meter, turbidity meter, beaker glass, magnetic stirrer, plate stirrer, pipet ukur dan gelas ukur.

Metode pengujian jar test pada air baku dilakukan dengan memasukan air sungai citarum sebanyak $2000 \mathrm{~mL}$ dan air bak wyne $500 \mathrm{~mL}$ kemudian diaduk. Bagi campuran air baku tersebut kedalam masing-masing $500 \mathrm{~mL}$ beaker glass. Letakan beaker gelas ke alat jar test, ukur $\mathrm{pH}$ dan turbidity sebelum dimulai jar test. Tambahkan sejumlah larutan koagulan dengan konsentrasi 5\% dengan ppm masing-masing 60, 65, 70,75 dan 80 mengikuti persamaan berikut ini:

$$
\begin{array}{l|c}
\text { Jumlah larutan koagulan : } & \text { nilai ppm } \times 0.5 \\
& \text { consentrasi koagular }
\end{array}
$$

Setelah ditambahkan larutan koagulan aduk dengan kecepatan $140 \mathrm{rpm}$ selama 1 menit. Kemudian tambahkan sejumlah larutan flokulan dengan konsentrasi $0,0714 \%$ dengan ppm yang sama 0,8 mengikuti persamaan berikut ini:

$$
\begin{array}{l|c}
\text { Jumlah larutan flokulan: } & \text { nilai } p p m \times 0.5 \\
\cline { 2 - 2 } & \text { consentrasi flokulan }
\end{array}
$$


Larutan yang telah ditambahkan flokulan diaduk dengan kecepatan $40 \mathrm{rpm}$ selama 10 menit. Lalu diamkan selama 5 menit dan ambil sebanyak $10 \mathrm{~mL}$ pindahkan ke beaker gelas $50 \mathrm{~mL}$. Kemudian lakukan pengukuran turbidity menggunakan turbidity meter. Selanjutnya setelah didiamkan 15 menit lakukan kembali pengukuran nilai turbidity pada $10 \mathrm{~mL}$ air baku tersebut. Ukur nilai $\mathrm{pH}$ setiap sempel air, catat hasil $\mathrm{pH}$ yang diperoleh setelah dilakukan jar test.

\section{HASIL DAN PEMBAHASAN}

\section{Tingkat keasaman (pH) air baku}

Penambahan zat kimia flokulan dan koagulan pada air baku yang digunakan pada salah satu perusahaan kertas di kabupaten Karawang dapat mengakibatkan penurunan kadar keasaman air baku tersebut. Dengan melihat grafik pada gambar 1 menunjukan bahwa proses penambahan flokulan koagulan ini dapat menurunkan $\mathrm{pH}$ dari sebelum diangka $\pm 7,5$ menjadi $\pm 6,5$. Nilai akhir dari $\mathrm{pH}$ air baku setelah proses jar test ini telah susuai dengan standar baku mutu air (husaini, 2018). Nilai pH akhir setelah proses jar test menunjukan $\mathrm{pH}$ yang netral sehingga diharapkan tidak merusak lingkungan ataupun mengganggu untuk proses produksi selanjutnya. Dan juga nilai ini juga telah memenuhi standar baku mutu $\mathrm{pH}$ di perusahaan tersebut untuk diproses lebih lanjut yaitu $\mathrm{pH}$ (6.5 7.5).

Data hasil pengujian $\mathrm{pH}$ sebelum dan sesudah jar test dilakukan pengujian statistic dengan paired sampel test. Dari hasil uji statistika menggunakan paired sampel test pada tabel 1 bahwa kadar pH memiliki perubahan yang sigifikat dengan nilai (Sig.) < 0,05 maka H0 ditolak. Artiya terdapat pengaruh yang signifikat dari Jar test terdapat perubahan kadar $\mathrm{pH}$. Berdasarkan hasil pengolahan tersebut, maka dapat disimpulkan, Jar test memberikan pengaruh yang besar terhadap perubahan kadar $\mathrm{pH}$. Terlihat pada gambar 1 ada nya penurunan kadar $\mathrm{pH}$ hingga $10 \%$.

Tabel 1. Paired Samples Test (pH)

\begin{tabular}{|c|c|c|c|c|c|c|c|c|}
\hline & \multirow{3}{*}{ Mean } & \multicolumn{4}{|c|}{ Paired Differences } & \multirow{3}{*}{$\mathrm{t}$} & \multirow{3}{*}{$\mathrm{df}$} & \multirow{3}{*}{$\begin{array}{l}\text { Sig. (2- } \\
\text { tailed) }\end{array}$} \\
\hline & & \multirow{2}{*}{$\begin{array}{c}\text { Std. } \\
\text { Deviation }\end{array}$} & \multirow{2}{*}{$\begin{array}{l}\text { Std. } \\
\text { Error } \\
\text { Mean }\end{array}$} & \multicolumn{2}{|c|}{$\begin{array}{l}95 \% \text { Confidence Interval } \\
\text { of the Difference }\end{array}$} & & & \\
\hline & & & & Lower & Upper & & & \\
\hline $\begin{array}{rl}\text { Pair } 1 & \mathrm{pH} \_ \text {Awal - } \\
& \mathrm{pH} \text { Akhir }\end{array}$ & 1.13789 & .28590 & .06559 & 1.00009 & 1.27569 & 17.349 & 18 & .000 \\
\hline
\end{tabular}

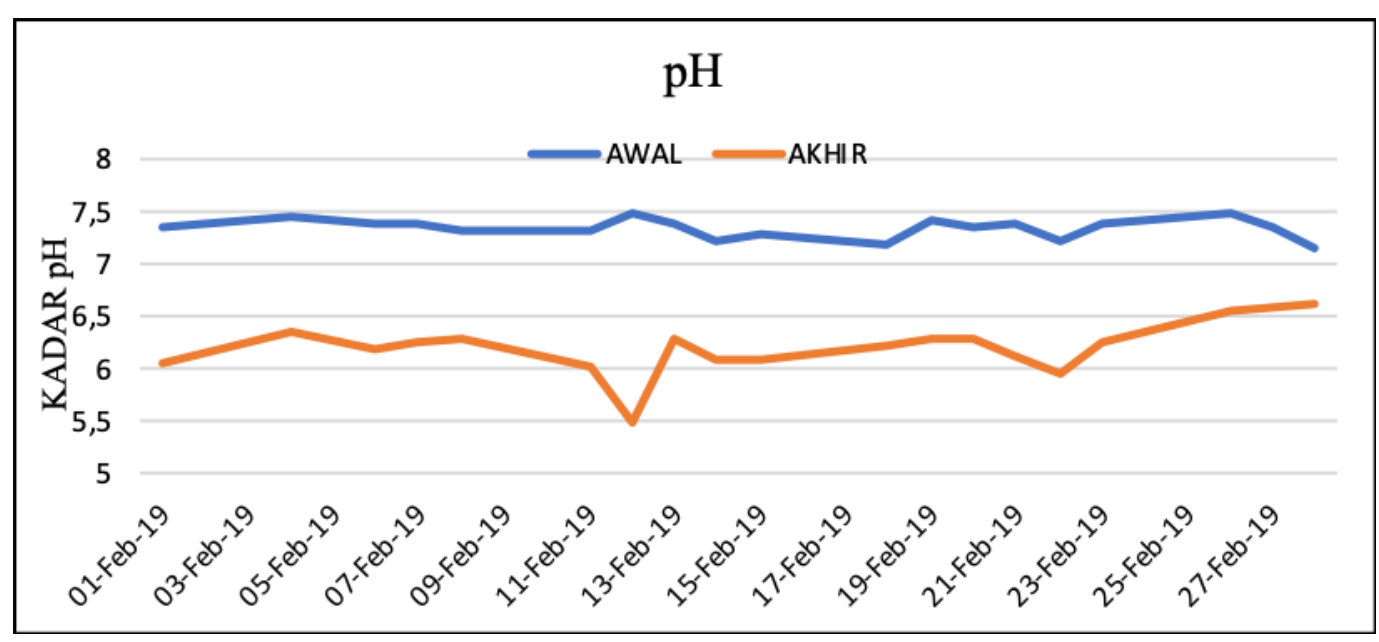

Gambar 1. Perubahan pH pada penambahan flokulan dan koagulan

\section{Turbidity air baku}

Salah satu parameter kualitas air ditentukan dari nilai kekeruhan air (turbidity). Penambahan flokulan dan koagulan disini berfungsi untuk memperbaiki kualitas airagar nilai turbidity nya menurun dan 
sesuai dengan nilai standar mutu air baku di perusahaan tersebut yaitu $<1,5 \mathrm{NTU}$. Zat flokulan dan koagulan yang digunakan mampu menurunkan turbidity air baku (sungai citarum) dari semula mencapai 469 NTU menjadi 3,68NTU (efisiensi penurunan 95\%). Keefektifan flokulan dan koagulan ini diakibatkan oleh kemampuan ion bermuatan positif yang dapat menarik partikel-partikel koloid bermuatan negatif yang terjadi pada rentang pH 5 hingga 8 (Mose, 2014).

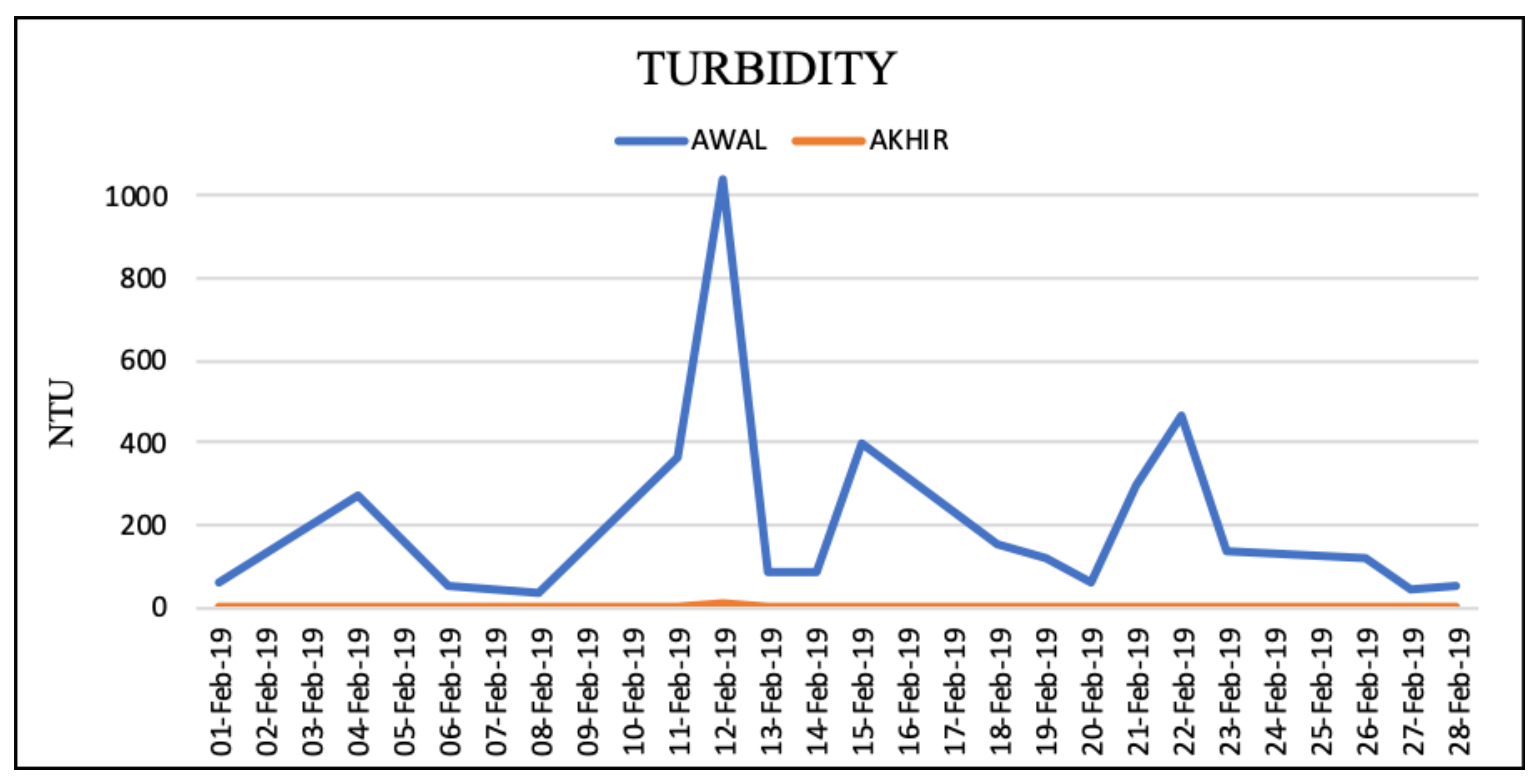

Gambar 2. Perubahan turbidity pada penambahan flokulan dan koagulan

Dengan melihat grafik pada gambar 2 menunjukan bahwa proses penambahan flokulan koagulan ini dapat menurunkan nilai turbidity mencapai $95 \%$. Nilai akhir dari turbidity air baku setelah proses jar test ini telah susuai dengan standar baku mutu air (Husaini, 2018). Semakin rendah nilai turbidity air maka semakin jernih air tersebut sehingga siap digunakan untuk proses produksi selanjutnya.

Dari data yang diperoleh selama penelitian dilakukan pengolahan data menggunakan metode paired samples test. Diketahui nilai t hitung kadar turbidity adalah 3.649 dengan probablitas (Sig.) 0,002 yang ditunjukkan pada Tabel 2. Adapun ketentuan pengambilan keputusan didasarkan pada beberapa ketentuan sebagai berikut (Santoso, 1999):

$\mathrm{H} 0=$ Tidak terdapat pengaruh yang signifikat dari Jar test terdapat perubahan NTU Turbidity.

H1 = Terdapat pengaruh yang signifikat dari Jar test terdapat perubahan NTU Turbidity.

Kriteria keputusan:

(a) Terima $\mathrm{H0}$ jika nilai probabilitas (Sig.) $>0.05$

(b) Tolak H0 jika nilai probabilitas (Sig.) $<0.05$

Nilai (Sig.) 0,002 < 0,05 maka H0 ditolak. Artiya terdapat pengaruh yang signifikat dari Jar test terdapat perubahan NTU Turbidity. Berdasarkan hasil pengolahan tersebut, maka dapat disimpulkan, Jar test memberikan pengaruh yang besar terhadap perubahan NTU Turbidity. Terlihat pada Gambar 2 adanya penurunan yang sangat signifikat dalam nilai kekeruhan air hingga $95 \%$.

\section{Tabel 2. Paired Samples Test (Turbidity)}

\begin{tabular}{|c|c|c|c|c|c|c|c|c|c|}
\hline \multicolumn{10}{|c|}{ Paired Differences } \\
\hline & & \multirow[t]{2}{*}{ Mean } & \multirow[t]{2}{*}{$\begin{array}{c}\text { Std. } \\
\text { Deviation }\end{array}$} & \multirow{2}{*}{$\begin{array}{l}\text { Std. } \\
\text { Error } \\
\text { Mean }\end{array}$} & \multicolumn{2}{|c|}{$\begin{array}{l}95 \% \text { Confidence } \\
\text { Interval of the } \\
\text { Difference }\end{array}$} & \multirow[t]{2}{*}{$\mathrm{t}$} & \multirow[t]{2}{*}{ df } & \multirow[t]{2}{*}{$\begin{array}{l}\text { Sig. (2- } \\
\text { tailed) }\end{array}$} \\
\hline & & & & & Lower & Upper & & & \\
\hline $\begin{array}{l}\text { Pair } \\
1\end{array}$ & $\begin{array}{l}\text { Turbidity_Awal - } \\
\text { Turbidity_Akhir }\end{array}$ & $\begin{array}{r}202.56 \\
737 \\
\end{array}$ & $\begin{array}{r}241.9563 \\
2 \\
\end{array}$ & 55.50859 & 85.94816 & $\begin{array}{r}319.1865 \\
8 \\
\end{array}$ & 3.649 & 18 & .002 \\
\hline
\end{tabular}




\section{Conductivity air baku}

Selain pengamatan terhadap nilai $\mathrm{pH}$ dan turbidity air baku sebelum dan sesudah penambahan flokulan dan koagulan dengan metode jar test, juga dilakukan pengamatan terhadap konduktivitas air baku tersebut. Dari pengamatan data yang diperoleh yang ditunjukan pada gambar 3, didapatkan bahwa penambahan flokulan dan koagulan tidak mempengaruhi secara signifikan pada besaran nilai konduktivitas air baku tersebut.

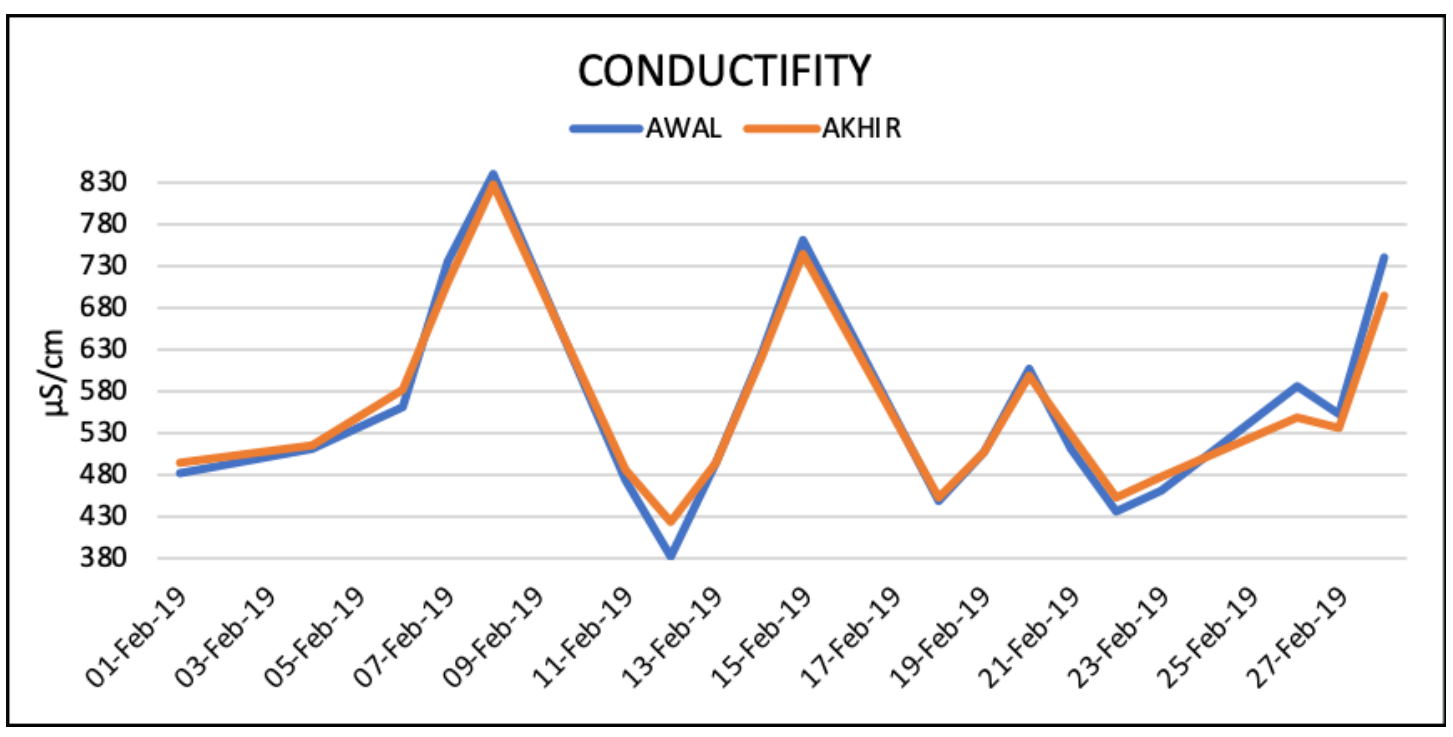

Gambar 3. Conductifity Hasil Jar Test

Tabel 3. Paired Samples Test Conductivity

\begin{tabular}{|c|c|c|c|c|c|c|c|c|c|}
\hline \multicolumn{10}{|c|}{ Paired Differences } \\
\hline & & \multirow[t]{2}{*}{ Mean } & \multirow[t]{2}{*}{$\begin{array}{c}\text { Std. } \\
\text { Deviation }\end{array}$} & \multirow{2}{*}{$\begin{array}{l}\text { Std. } \\
\text { Error } \\
\text { Mean }\end{array}$} & \multicolumn{2}{|c|}{$\begin{array}{l}95 \% \text { Confidence } \\
\text { Interval of the } \\
\text { Difference }\end{array}$} & \multirow[t]{2}{*}{$\mathrm{t}$} & \multirow[t]{2}{*}{ df } & \multirow[t]{2}{*}{$\begin{array}{l}\text { Sig. (2- } \\
\text { tailed) }\end{array}$} \\
\hline & & & & & Lower & Upper & & & \\
\hline $\begin{array}{c}\text { Pair } \\
1\end{array}$ & $\begin{array}{l}\text { Conductifity_Awal - } \\
\text { Conductifity_Akhir }\end{array}$ & $\begin{array}{c}1.273 \\
7\end{array}$ & 21.6351 & $\begin{array}{c}4.963 \\
4\end{array}$ & -9.1541 & 11.7015 & .257 & 18 & .800 \\
\hline
\end{tabular}

Dari pengujian data konduktivitas sampel sebelum dan setelah jar test menggunakan metode paired samples test menunjukan nilai t hitung Conductifity adalah 0.257 dengan probablitas (Sig.) 0,800. Nilai (Sig.) $0,800>0,05$ maka Ho terima. Artinya tidak terdapat pengaruh yang signifikan dari Jar test terdapat perubahan conductifty. Berdasarkan hasil pengolahan tersebut, maka dapat disimpulkan, Jar test memberikan pengaruh yang besar terhadap perubahan conductifity. Terlihat pada gambar 3. tidak ada perubahan signifikan pada conductifity.

\section{KESIMPULAN}

Pada pengelohan air baku yang dilakukan pad salah satu perusahaan kertas di kabupaten karawang meliputi pengolahan secara fisik. Pengolahan fisik yang dilakukan yaitu proses pembentukan gumpalan-gumpulan (flok-flok) sehingga akan terjadi proses pengendapan. Instalasi pengolahan air baku terdiri dari proses koagulasi, flokulasi, sedimentasi, sand filter, dan carbon filter lalu ke bak Fresh Water. Agar mendapat kualitas air dengan baik maka dilakukan penambahan larutan koagulan dan larutan flokulan karena larutan ini dapat menurunkan tingkat kekeruhan air. Curah hujan yang tinggi menyebabkan waktu Jar test yang lebih lama. Dikarenakan air sungai citarum yang meluap tercampur dengan material lumpur, limbah, dan lain-lain. Kondisi ini sangat mengganggu di proses pengolahan air baku. Oleh karena itu diperlukan jar test untuk mencari titik optimum penggunaan bahan kimia (koagulan \& flokulan) dan jumlah air sungai citarum yang akan di pakai. Hasil pegamatan selama kerja praktek, diketahui Jar test dapat menurukan Turbidity hingga mencapai 
95\% dan $\mathrm{pH} 10 \%$. Hasil ini dengan menggunakan uji statistika paired sampel test kadar $\mathrm{pH}$ dan Turbidity memiliki nilai (Sig.) 0,000 $<0,05$ maka Ho ditolak yang artiya terdapat pengaruh yang signifikat dari Jar test terhadap nilai pH dan turbidity. Namun conductifity memiliki nilai (Sig.) 0,800 $>$ 0,05 maka Ho terima. Artinya tidak terdapat pengaruh yang signifikat dari Jar test terdapat perubahan conductifty.

\section{DAFTAR PUSTAKA}

Husaini, Stefanus S., Suganal dan Kukuh N. (2018). "Perbandingan Koagulan Hasil Percobaan Dengan Koagulan Komersial Menggunakan Metode Jar Test" Jurnal Teknologi Mineral dan Batubara, Vol 14: 31-45

Mose, Y. (2014). "Penerapan model pembelajaran predict-observe-explain (POE) pada materi koloid untuk meningkatkan keterampilan berpikir kritis dan keterampilan proses sains siswa". Universitas Pendidikan Indonesia.

Santoso, Singgih. (1999). SPSS: Mengolah Data Statistik Secara Profesional Versi 7.5. Jakarta: Elex Media Komputindo.

Sutrisno, Totok. (2010). Teknologi Penyediaan air Bersih. Jakarta : CV Rineka Cipta 